\title{
Zika e microcefalia no Facebook da Fiocruz: a busca pelo diálogo com a população e a ação contra os boatos sobre a epidemia
}

\author{
Zika and microcephaly on Fiocruz's Facebook: the search for dialogue \\ with the population and the action against rumors about the epidemic
}

\section{Zika y microcefalia en Facebook de Fiocruz: la búsqueda por el diálogo con la población y la acción contra los rumores sobre la epidemia}

Paloma da Silva Barreto ${ }^{1, a}$

palomasilbar@gmail.com | http://orcid.org/0000-0003-0765-9820

Luís Amorim ${ }^{1, b}$

lha2000@gmail.com | https://orcid.org/o000-0003-3964-1844

Marcelo Pereira Garcia ${ }^{2, c}$

email.marcelogarcia@gmail.com | http://orcid.org/o000-0001-6183-2343

Carla Almeida ${ }^{1, d}$

carla.almeida@fiocruz.br | http://orcid.org/0000-0003-3139-0331

\footnotetext{
${ }^{1}$ Fundação Oswaldo Cruz, Casa de Oswaldo Cruz, Museu da Vida. Rio de Janeiro, RJ, Brasil.

2 Fundação Oswaldo Cruz, Instituto de Comunicação e Informação Científica e Tecnológica em Saúde.

Rio de Janeiro, RJ, Brasil.

a Graduação em Comunicação Social (Jornalismo) pela Universidade Federal do Rio de Janeiro.

b Mestrado em Comunicação, Ciência e Mídia pela Fundação Oswaldo Cruz.

c Mestrado em Informação e Comunicação em Saúde pela Fundação Oswaldo Cruz.

d Doutorado em Química Biológica pela Universidade Federal do Rio de Janeiro.
}

\section{Resumo}

Este artigo analisa a abordagem da epidemia de zika e microcefalia pela página da Fundação Oswaldo Cruz no Facebook entre maio de 2015 e maio de 2016. Seguindo procedimentos da análise de conteúdo, destacamos características das postagens sobre o tema a partir de sua frequência, enquadramento, formato e engajamento. Também analisamos qualitativamente parte dos comentários das postagens de maior engajamento. Os resultados mostram o destaque recebido pelo tema na página e evidenciam a priorização do enfoque científico e político-institucional, o emprego da ciência para conferir credibilidade aos conteúdos e a popularidade das postagens sobre boatos junto ao público. Constatou-se, ainda, pouca interação por parte da Fiocruz e pequena variação dos formatos empregados nas postagens, com priorização de recursos tradicionais.

Palavras-chave: Comunicação e saúde; Divulgação científica; Zika; Microcefalia; Facebook. 


\begin{abstract}
This article analyzes how Oswaldo Cruz Foundation's page on Facebook approached the epidemic of zika and microcephaly between May 2015 and May 2016. Following procedures of the content analysis, we highlight characteristics of the posts on the topic based on their frequency, frame, format and engagement. We also qualitatively analyze part of the comments of the posts with the highest level of engagement. The results show the great attention received by the theme on the page and bring to evidence the prioritization of the scientific and political-institutional frame, the use of science to confer credibility to the content and the popularity of the posts about rumors among the public. There was also little interaction on the part of Fiocruz and small variation of the formats used in the posts, with prioritization of traditional resources.
\end{abstract}

Keywords: Communication and health; Science Communication; Zika; Microcephaly; Facebook.

\title{
Resumen
}

Este artículo analiza el enfoque de la epidemia de zika y microcefalia por la página de la Fundación Oswaldo Cruz en Facebook entre mayo de 2015 y mayo de 2016. Siguiendo procedimientos del análisis de contenido, destacamos características de las publicaciones sobre el tema a partir de su frecuencia, encuadramiento, formato y participación. También analizamos cualitativamente parte de los comentarios de las publicaciones de mayor participación. Los resultados muestran el destaque recibido por el tema en la página y evidencian la priorización del enfoque científico y político-institucional, el empleo de la ciencia para conferir credibilidad a los contenidos y la popularidad de los postes sobre rumores ante el público. Se constató, además, poca interacción por parte de la Fiocruz y pequeña variación de los formatos empleados en las publicaciones, con priorización de recursos tradicionales.

Palabras clave: Comunicación y salud; Divulgación científica; Zika; Microcefalia; Facebook.

Este artigo compõe o Dossiê Fake News e Saúde.

Contribuição dos autores:

Concepção e desenho do estudo: Paloma da Silva Barreto, Luís Amorim, Marcelo Pereira Garcia.

Aquisição, análise ou interpretação dos dados: Paloma da Silva Barreto, Luís Amorim, Marcelo Pereira Garcia, Carla Almeida.

Redação do manuscrito: Paloma da Silva Barreto, Luís Amorim, Marcelo Pereira Garcia, Carla Almeida.

Revisão crítica do conteúdo intelectual: Paloma da Silva Barreto, Luís Amorim, Marcelo Pereira Garcia, Carla Almeida.

Declaração de conflito de interesses: não há.

Fontes de financiamento: não houve.

Considerações éticas: não há.

Agradecimentos/Contribuições adicionais: não há.

Histórico do artigo: submetido: 23 abr. 2019 | aceito: 30 set. 2019 | publicado: 31 mar. 2020.

Apresentação anterior: não houve.

Licença CC BY-NC atribuição não comercial. Com essa licença é permitido acessar, baixar (download), copiar, imprimir, compartilhar, reutilizar e distribuir os artigos, desde que para uso não comercial e com a citação da fonte, conferindo os devidos créditos de autoria e menção à Reciis. Nesses casos, nenhuma permissão é necessária por parte dos autores ou dos editores. 


\section{Introdução}

O tema zika/microcefalia foi um dos assuntos mais relevantes no noticiário nacional no verão de 2015-2016 e levantou questões importantes a serem pensadas pelos campos da comunicação e saúde e divulgação científica, como a validação de discursos pela ciência, as limitações do conhecimento científico, a ascensão de informações de veracidade duvidosa e suas consequências, entre outras, como mostram Aguiar e Araújo ${ }^{1}$. Como instituição pública de pesquisa e promoção da saúde, a Fundação Oswaldo Cruz (Fiocruz) teve papel de destaque neste cenário por suas pesquisas e resultados científicos no campo e, do ponto de vista comunicacional, utilizou sua página no Facebook para uma interação mais direta com a população - a despeito de seus esforços de assessoria de imprensa e da presença da instituição mediada pela mídia.

O entendimento sobre qualquer aspecto da comunicação contemporânea passa necessariamente pela consideração das mudanças acarretadas pelo advento das novas tecnologias de informação e comunicação. Da perspectiva da divulgação científica, é importante notar, como mostra a enquete - 'Percepção Pública da Ciência e Tecnologia no Brasil'², que a internet e as redes sociais já são o segundo principal meio de acesso à informação sobre C\&T para os brasileiros. Entre as redes sociais, o Facebook - plataforma que é objeto deste estudo - se apresenta como uma das que gozam de maior popularidade no Brasil ${ }^{3}$.

Neste artigo, analisamos a inserção do tema 'zika-microcefalia' na página oficial da Fiocruz na rede social Facebook. A partir das postagens da página realizadas entre maio de 2015 e maio de 2016, período que compreende um ciclo completo da epidemia - desde as primeiras notícias sobre a doença, passando pelo seu auge, até o início do seu período de latência no inverno seguinte -, buscamos responder às seguintes questões: quais as abordagens utilizadas pela Fiocruz? Quais as principais características das postagens que tratam do tema em termos de formato e conteúdo? Como foi a interação entre o público e a instituição?

\section{Sobre a zika}

Descoberto na Uganda, em $1947^{4}$, o vírus zika teve sua presença confirmada no país em maio de 2015. A enfermidade em questão é conhecida como febre zika ou apenas zika, uma virose da mesma família da dengue e chikungunya. Em comum, além de alguns dos sintomas, elas compartilham o principal meio de transmissão, a picada do mosquito da espécie Aedes aegypti. Desconhecida até então pelos profissionais de saúde, a infecção ficou caracterizada pela sua semelhança com a dengue - embora mais branda - e por causar manchas vermelhas na pele. Inicialmente, a zika não causou preocupação às autoridades de saúde, já que apenas $20 \%$ das pessoas infectadas desenvolvem os sintomas.

Em outubro de 2015, no entanto, com o aumento no número de notificações de nascimento de bebês com microcefalia em regiões do Brasil afetadas pela zika, especialistas começaram a suspeitar da relação com a infecção pelo vírus - cenário confirmado por descobertas científicas divulgadas no mês seguinte 5 . A partir daquele momento, o vírus zika se tornou uma importante questão de saúde pública dentro e fora do país - em novembro de 2015 o Ministério da Saúde decretou Emergência em Saúde Pública de Importância Nacional e em fevereiro de 2016 a Organização Mundial de Saúde considerou o avanço da microcefalia ligada à zika situação de emergência internacional ${ }^{6}$. O surto de zika ganhou então a atenção da mídia nacional e internacional, conforme pesquisas como a de Aguiar e Araújo ${ }^{1}$, e teve enorme repercussão nas redes sociais, como mostram estudos como o de Garcia7.

Os meses seguintes às primeiras suspeitas da relação entre a epidemia de zika e o aumento dos casos de microcefalia foram caracterizados por grandes incertezas, que persistiram (ou até aumentaram) mesmo após a confirmação dessa hipótese. Diante de uma emergência epidemiológica, em que a comunidade científica era incapaz de responder a todas as questões da sociedade, multiplicaram-se os boatos, disseminando medo na população e preocupando as organizações da área da saúde. Em especial pelo 
aplicativo de mensagens instantâneas WhatsApp, textos e áudios com conteúdo sem fundamento científico e informações extraoficiais ganharam circulação, apresentando narrativas que, por exemplo, relacionavam a microcefalia à aplicação de vacinas vencidas ou ao uso de determinados larvicidas.

O episódio reflete o processo de midiatização que atinge, em maior ou menor grau, todos os campos da atuação humana. Mais especificamente na área da saúde, como escreve Antunes ${ }^{8}$, a compreensão sobre os processos de produção, formulação e circulação de sentidos está condicionada à multiplicidade das materialidades semiológicas, ou seja, jornais, TV, internet, todos os media sobredeterminam de um modo dinâmico e complexo o que compreendemos por saúde, doença, bem e mal-estar. A emergência da zika desperta e evidencia diversas questões que relacionam comunicação, ciência, saúde e sociedade. Dentre elas, destaca-se a abordagem das incertezas científicas numa configuração social contemporânea em que a ciência não é suficiente para garantir as certezas, e o Estado é visto como limitado em sua capacidade política e de proteção, destaca Antunes ${ }^{8}$.

\section{As redes sociais e a comunicação sobre ciência e saúde}

Para pensar qualquer aspecto ou tema dentro da comunicação contemporânea, é preciso considerar o enorme impacto promovido pelas novas mídias. Segundo o Centro Regional de Estudos para o Desenvolvimento da Sociedade da Informação, a maior parte dos domicílios brasileiros (51\%) tem acesso à internet, e o país tem pouco mais de 100 milhões de usuários, números que vêm crescendo a cada ano9. O uso de redes sociais, como o Facebook, foi citado por $77 \%$ dos entrevistados como uma das atividades praticadas na internet. Segundo a enquete mais recente sobre 'Percepção Pública da Ciência e Tecnologia no Brasil'2, o tema 'Medicina e Saúde' é o que mais desperta interesse dos brasileiros, e a internet já é o segundo principal meio de acesso à informação de ciência e tecnologia.

Dessa forma, acreditamos que a internet pode ser grande aliada no engajamento público em temas de ciência e saúde. Para Nisbet e Scheufele $\mathrm{e}^{10}$, as novas mídias digitais têm o potencial para mobilizar indivíduos e aumentar a participação do público em debates sobre temas que envolvem a ciência. Para Garbin, Guilam e Neto ${ }^{11}$, que discorreram sobre o uso da internet para promoção da saúde, o acesso à diversidade de informações e ferramentas possibilita que o indivíduo seja o agente do próprio processo de aquisição de conhecimentos. Autores como Wilcox ${ }^{12}$ acreditam no poder das redes digitais para mudar o paradigma de distanciamento entre ciência e público, algo também observado por Antunes et al. ${ }^{13}$.

Por outro lado, os estudos sobre a internet e as redes sociais também consideram os pontos negativos e armadilhas proporcionados pela expansão da internet e da web 2.o. Garbin, Guilam e Neto ${ }^{11}$ destacam a desigualdade de acesso aos meios digitais como fator de reprodução das formas de exclusão já existentes. Além disso, problematizam a qualidade da informação oferecida (por vezes incompleta, contraditória, incorreta ou fraudulenta), questionam se a internet não reforça a intensa medicalização da sociedade e problematizam o possível empoderamento do usuário, que poderia levar à extrema individualização de questões que devem estar relacionadas a políticas de saúde pública.

Um dos focos dos esforços da comunicação e da divulgação da ciência e saúde na internet sem dúvida deve ser o Facebook, rede social mais popular do mundo na atualidade. Criado em 2004, o Facebook atingiu a marca de um bilhão de usuários ativos diariamente em 2016 ${ }^{14}$. Um levantamento do próprio Facebook apontou que 99 milhões de brasileiros acessam a plataforma pelo menos uma vez ao mês e que oito em cada 10 brasileiros conectados estão nessa rede. Para Recuero ${ }^{15}$, as redes sociais, como o Facebook, precisam ser pensadas enquanto suas características como meio de difusão de informação, para além dos conteúdos que são disseminados, e produzem quatro efeitos intrínsecos. O primeiro é a formação de cascatas de compartilhamento de conteúdos, que afetam exponencialmente a circulação de informações; o segundo é a descentralização da produção dessas informações (e a consequente criação de estruturas de filtragem, que 
no Facebook correspondem a seu próprio sistema de algoritmos). Em terceiro lugar, a interconexão entre as diversas audiências de uma rede social, com a confusão entre os polos emissores e receptores do processo de comunicação. E, por fim, a replicação de informações e conteúdos de outro meio, com a divulgação de links que direcionam o público a sites externos.

\section{Metodologia}

Neste trabalho, como já foi mencionado, será analisada a página da Fiocruz no Facebook. Fundação pública federal de ciência e tecnologia vinculada ao Ministério da Saúde, a Fiocruz está presente em diversos estados brasileiros. Em 2006 foi eleita a melhor instituição de saúde pública do mundo pela Federação Mundial das Associações de Saúde Pública ${ }^{16}$ e, segundo ranking da Universidade de Leiden, na Holanda, a Fiocruz é o melhor instituto de pesquisa no Brasil em termos de qualidade de produção científica ${ }^{17}$. Na enquete sobre 'Percepção Pública da Ciência e Tecnologia no Brasil' supracitada, a Fiocruz é a instituição científica mais mencionada pelos entrevistados. Em 2015, a Fiocruz foi laureada com o Prêmio José Reis de Divulgação Científica e Tecnológica, na categoria "Instituição ou Veículo de Comunicação"18. O prêmio anual, concedido pelo Conselho Nacional de Desenvolvimento Cientifico e Tecnológico (CNPq) desde 1978, é destinado a iniciativas que contribuam significativamente para tornar a ciência, a tecnologia e a inovação conhecidas do grande público. A página da Fiocruz no Facebook, que em junho de 2018 chegava a cerca de 120 mil seguidores, possuía em torno de 80 mil seguidores no momento da epidemia.

Quando uma instituição cria uma fanpage no Facebook, ela passa a poder compartilhar os mais variados tipos de conteúdos com os outros usuários da rede social. Nesta investigação, dedicamo-nos a analisar as publicações da página do Facebook da Fiocruz sobre o tema zika-microcefalia. Inicialmente, por meio do Netvizz, aplicativo oferecido dentro do próprio Facebook, coletamos dados referentes aos últimos 999 posts (número máximo que o software permite obter), contados retroativamente a partir do dia do download (28/07/2016). Foram extraídas informações como data, mensagem, tipo de postagem, número de comentários, curtidas, compartilhamentos, entre outras, de posts publicados entre 24 de fevereiro de 2015 e 28 de julho de 2016.

Posteriormente, realizamos uma triagem dessas publicações, selecionando apenas aquelas que mencionassem o termo 'zika' e/ou 'microcefalia'. Estipulamos como corpus da pesquisa as postagens publicadas da primeira menção ao termo zika, observada em 14 de maio de 2015, até maio de 2016, completando um período de um ano. Entendemos que este período abrange um ciclo que começa com a descoberta do vírus da zika no Brasil, passa pelo período de pouca visibilidade inicial, pela explosão no verão seguinte, com a descoberta da associação com a microcefalia e termina no início de um novo período de latência, com o fim do período mais quente do ano. O corpus final obtido é composto por 132 posts.

A análise de conteúdo realizada neste trabalho baseia-se nos moldes preconizados por $\operatorname{Bardin}^{19}$. Essa metodologia permite mapear cada unidade de análise de acordo com os aspectos considerados relevantes para a pesquisa. A reunião dessas análises formará um panorama a ser explorado na apresentação dos resultados. A construção do protocolo utilizado foi baseada em dois estudos consultados durante a revisão bibliográfica. Em Ramalho et al. ${ }^{20}$, este método foi elaborado para ser aplicado às notícias de ciência e tecnologia veiculadas por telejornais de países da Ibero-América. Já em Rocha ${ }^{21}$, o modelo desenvolvido foi utilizado para a análise de postagens no Facebook de museus de ciência brasileiros.

A primeira dimensão deste protocolo se atém, exclusivamente, a identificar cada unidade de análise a partir da data de sua publicação no Facebook e de uma breve descrição de sua mensagem. A segunda, 'Enquadramento', é composta por oito categorias de classificação temática (novidades/resultados/ descobertas; orientações/dúvidas/informações; eventos científicos; boatos/esclarecimentos; boletim de microcefalia; zika em periódicos/imprensa; questões políticas e/ou institucionais; ações/serviços), sendo 
que um mesmo post poderia se encaixar em mais de uma das categorias. A terceira, 'Formato', identifica quais os recursos utilizados pela edição da página para veicular as postagens (texto, imagem, link, vídeo, hashtag ou outro), de modo que também havia a possibilidade de um post se encaixar em mais de uma categoria. Por fim, em 'Engajamento', procurou-se mensurar o volume de interações que a audiência manteve com os posts por meio da soma dos números de curtidas, comentários e compartilhamentos de cada postagem. Apesar de cada uma dessas formas de engajamento apresentar significados distintos do ponto de vista da interação entre o público e a página, este trabalho não se aprofundará nessa diferenciação ou mesmo criará um método de hierarquização entre elas. Além disso, não temos pretensão de detalhar aqui o comportamento da audiência ou as estatísticas de alcance da página.

De forma complementar, realizamos uma análise qualitativa dos cinco posts que obtiveram o maior engajamento dentre os 132 selecionados, na qual examinamos mais atentamente as interações entre o público e a página nessas postagens. Para tanto, lemos os comentários publicados em cada uma delas, assim como as respostas da página da Fiocruz - quando havia respostas - também nesse espaço de interação. Como seria impossível analisar o total de comentários nas cinco postagens, que variou entre 50 e 3 mil, aproximadamente, delimitamos o estudo ao conteúdo dos dez primeiros comentários que aparecem em cada post. Pelo que foi possível observar, no caso de posts da página da Fiocruz, a ordem dos comentários parece estar relacionada ao nível de engajamento de cada comentário e não à sua data de publicação. Por isso, é possível dizer que os dez comentários objetos da análise qualitativa são os mais relevantes em termos de interação com outros usuários e com a própria página da Fiocruz.

\section{Resultados da análise dos posts}

Seguindo o passo a passo do protocolo apresentado na seção anterior, organizamos os resultados da análise quantitativa das postagens em quatro dimensões: frequência, enquadramento, formato e engajamento.

\section{Frequência}

Neste tópico, analisamos a frequência das postagens sobre zika/microcefalia na página da Fiocruz no Facebook, relacionando-as ao universo total de publicações realizadas nesta rede. Durante o período considerado neste estudo, a Fiocruz fez 720 postagens, porém, com certa variação de frequência conforme cada mês e cada dia da semana analisados. Nos meses com mais atividade (maio/2015, outubro/2015 e novembro/2015) foram publicados 84, 77 e 74 posts, respectivamente. Enquanto isso, o mês de agosto/2015 registrou o menor índice de publicações, apenas 17. Vale pontuar que, entre julho e agosto de 2015, houve greve dos servidores da Fiocruz, e a página do Facebook chegou a ficar 18 dias seguidos sem atividade.

Entre toda a atividade da página no período analisado, 132 postagens abordam o tema zika e/ou microcefalia. Isto significa que aproximadamente um quinto das publicações realizadas pela Fiocruz na sua página do Facebook, entre maio/2015 e maio/2016, falavam sobre o assunto. No entanto, essa proporção também variou bastante: enquanto não houve menções em julho/2015, agosto/2015 e setembro/2015, por exemplo, em novembro/2015, dezembro/2015, janeiro/2016 e fevereiro/2016 posts sobre zika representaram $21 \%, 41 \%, 45 \%$ e $60 \%$ do total de postagens, respectivamente.

Os dados nos permitem concluir que o tema zika/microcefalia teve grande destaque na página da Fiocruz no Facebook a partir de novembro de 2015, após os indícios de que a doença teria associação com o aumento no número de casos de microcefalia, seguidos pela oficialização desta tese pelos órgãos de saúde. Em seguida, com a chegada do verão e a explosão do número de casos, o tema continuou em alta. Uma vez que a instituição esteve diretamente envolvida na pesquisa e desenvolvimento tecnológico relacionados à epidemia, conforme esperávamos, a página da Fiocruz acompanhou a cobertura da imprensa e o deslocamento da atenção pública, que se intensificaram com as novidades da associação das duas doenças, 
resultados científicos e com o próprio debate sobre as perspectivas que a epidemia de uma enfermidade pouco conhecida como a zika suscitou. Em abril e maio de 2016, no entanto, a atenção ao tema se mostra menor, embora não seja possível confirmar uma tendência de queda sem a análise dos meses seguintes.

\section{Enquadramento}

Este tópico trata da temática das postagens, enquadradas a partir das categorias definidas no tópico de metodologia. Em 21 das 132 publicações, o post foi classificado em mais de uma categoria. O recorte 'novidades/resultados/descobertas' foi o que teve maior número de ocorrências: 34 casos. A categoria 'Questões Políticas e/ou Institucionais' veio logo em seguida, com 32 publicações, ficando a temática ‘Eventos científicos’ em terceiro lugar, com 21 registros. No Gráfico 1, é possível conferir o número absoluto de posts classificados em cada categoria.

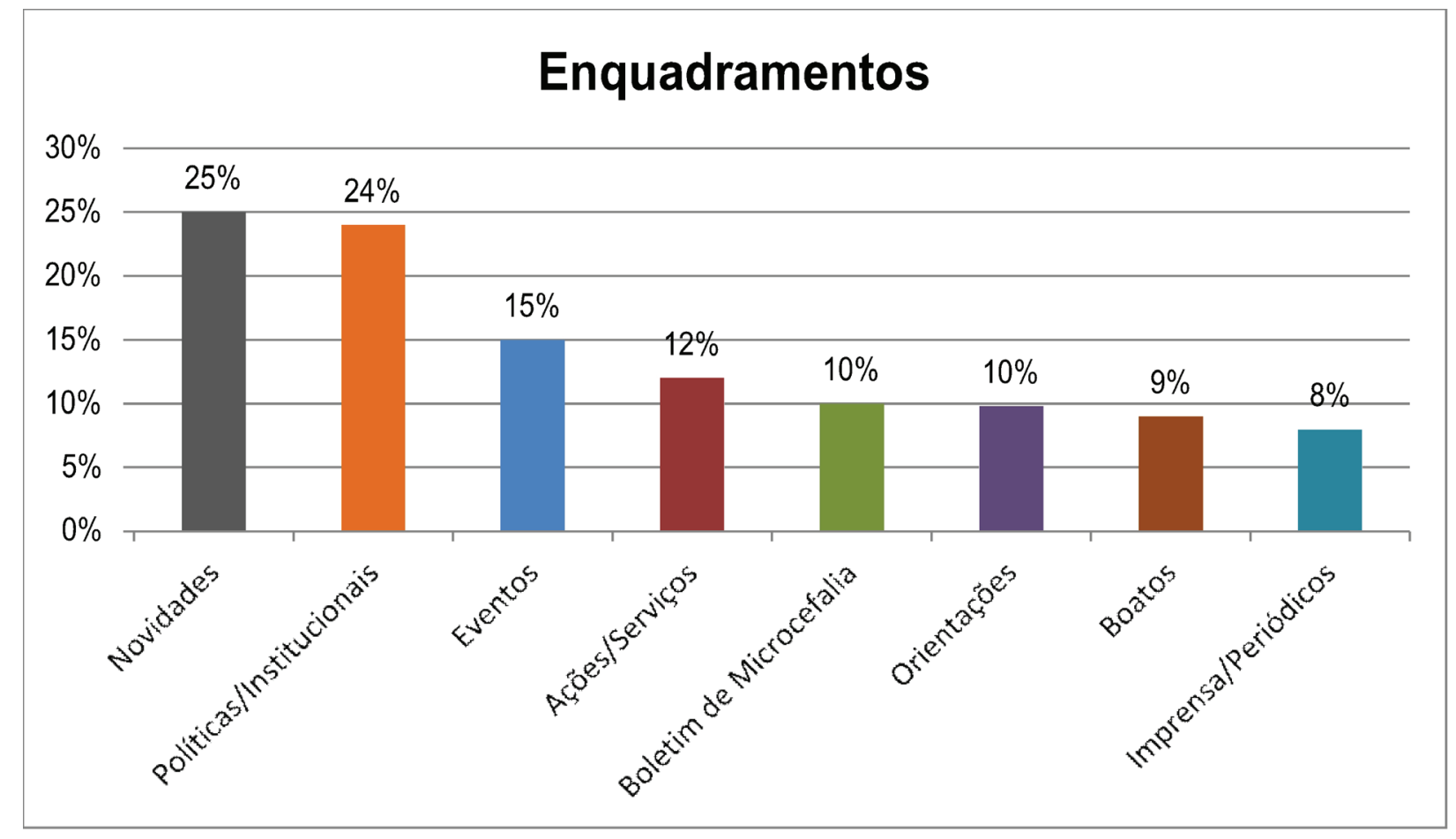

Gráfico 1 - Percentual de presença dos enquadramentos nos posts* sobre zika/microcefalia Fonte: Os autores (2017).

*Total de posts: 154.

Os tipos de enquadramentos identificados e o número de ocorrência de cada um deles refletem, de certa forma, características da própria epidemia de zika/microcefalia e evidenciam as prioridades de abordagem e tratamento da questão pela Fiocruz no Facebook. No contexto de uma epidemia causada por um vírus pouco conhecido, a Fiocruz se destacou como entidade responsável por importantes descobertas científicas, desenvolvimento de inovações e proposição de políticas públicas de combate à epidemia. Em sua página do Facebook, foram priorizadas as abordagens do ponto de vista científico, com a divulgação de resultados de pesquisas, eventos acadêmicos e inovações tecnológicas; e político-institucional, com a publicação de conteúdos do Ministério da Saúde e do Governo Federal.

Nesse contexto, chamou-nos especial atenção o espaço dedicado ao esclarecimento de boatos e de divulgação de informações básicas sobre zika/microcefalia nas postagens analisadas, o que indica a proposta da Fiocruz de dialogar com um público amplo, para além de sua rede de vínculos acadêmicos e científicos. Especificamente sobre boatos, é preciso destacar que as incertezas e dúvidas despertadas sobre 
o tema, em conjunto com a facilidade de disseminação de informações possibilitada pelas redes sociais, criaram um ambiente propício para a multiplicação de conteúdos sem fundamentação científica, como também identificado por Aguiar e Araújo ${ }^{1}$ e por Garcia7. Como problematizado por Garbin, Guilam e Neto ${ }^{11}$, tal realidade corrobora a ideia de que parte das informações presentes na internet apresenta qualidade questionável e é oriunda de fontes com pouca ou nenhuma credibilidade. Ao procurar combater os boatos em circulação, a Fiocruz se insere ativamente na produção da narrativa sobre a epidemia de zika/microcefalia, que teve nas redes sociais importante campo de disputa.

\section{Formato}

Das 132 postagens, 120 apresentam algum tipo de imagem, seja compartilhada por upload (80 casos) ou pelo carregamento automático de um link (40 postagens). O tipo de imagem mais utilizado é a fotografia, como de mosquitos, eventos, autoridades, laboratórios, entre outras. Além disso, há 22 ocorrências de flyers eletrônicos, em geral com informações sobre eventos e ações. Também foi observado, em casos particulares, o uso de infográficos, quadrinhos e tabelas.

Um forte viés institucional está presente em, pelo menos, 32 das imagens publicadas. Aparecem, com frequência, fotografias de unidades da Fiocruz, da presidência e do corpo diretor da Fiocruz, de autoridades políticas, entre outros exemplos. Já em 22 casos, as imagens propagam signos da ciência e medicina, como laboratórios, cientistas, médicos etc. Há, ainda, 10 imagens de mosquito, que fazem alusão direta ao principal vetor da doença. Esses dados, consolidados no Gráfico 2, mostram que a página é utilizada para fortalecer a imagem da instituição e também se vale da credibilidade da Fiocruz e da confiança associada aos símbolos científicos para tentar diminuir a insegurança e a incerteza do momento de crise. Assim como Antunes et al. (2016) apontam em seu estudo sobre a representação imagética da epidemia no Instagram, imagens relacionadas à gravidez também são recorrentes no Facebook da Fiocruz: 17 registros trazem gestantes e/ou recém-nascidos, em plano detalhe da barriga, da amamentação ou da cabeça dos bebês, fortalecendo a relação entre zika e microcefalia.

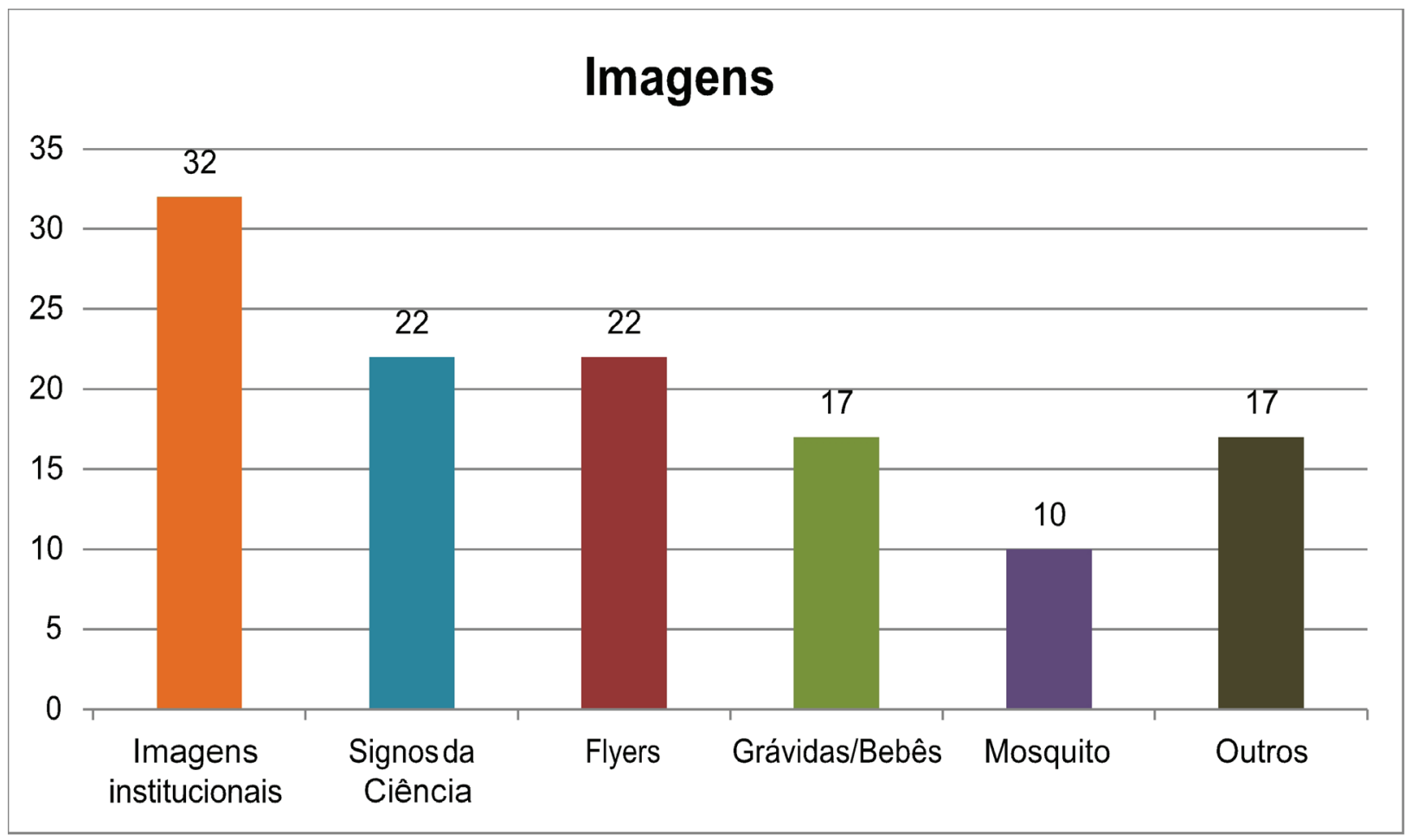

Gráfico 2 - Número de ocorrência de imagens retratando determinados conteúdos Fonte: Os autores (2017). 
Todas as postagens possuem algum texto, e a utilização de links também é bastante comum, aparecendo em 114 posts. Destes, 99 direcionam para o site da Agência Fiocruz de Notícias - muitas vezes para textos publicados em outros canais de comunicação das unidades da Fiocruz e reproduzidos na agência, não havendo praticamente nenhum direcionamento a conteúdos de outras fontes. A utilização de vídeos que rodem diretamente na página do Facebook (e não de links para vídeos em outras plataformas) é pequena (há apenas 10 ocorrências), e foram feitas cinco transmissões ao vivo no período, em geral de coletivas de imprensa. Já o uso de hashtags ocorreu em 109 postagens e foram utilizadas 216 hashtags no total (com repetições), com desataque para \#zika, com 76 aparições, seguida por \#microcefalia (30), \#chikungunya (22), \#dengue (20), \#Aedes (10) e \#AedesAegypti (10). Outras hashtags se referem a unidades, institutos e publicações da Fiocruz, como \#FiocruzPernambuco e \#InformeENSP. Nenhum outro recurso, como gifs animados, memes, ou alteração de status, foram utilizados nos posts sobre zika/microcefalia. Os percentuais de utilização de cada tipo de recurso de formato estão consolidados no Gráfico 3. Em suma, a página da Fiocruz optou por formatos mais tradicionais, com pouca variação e experimentação nesta dimensão do Facebook.

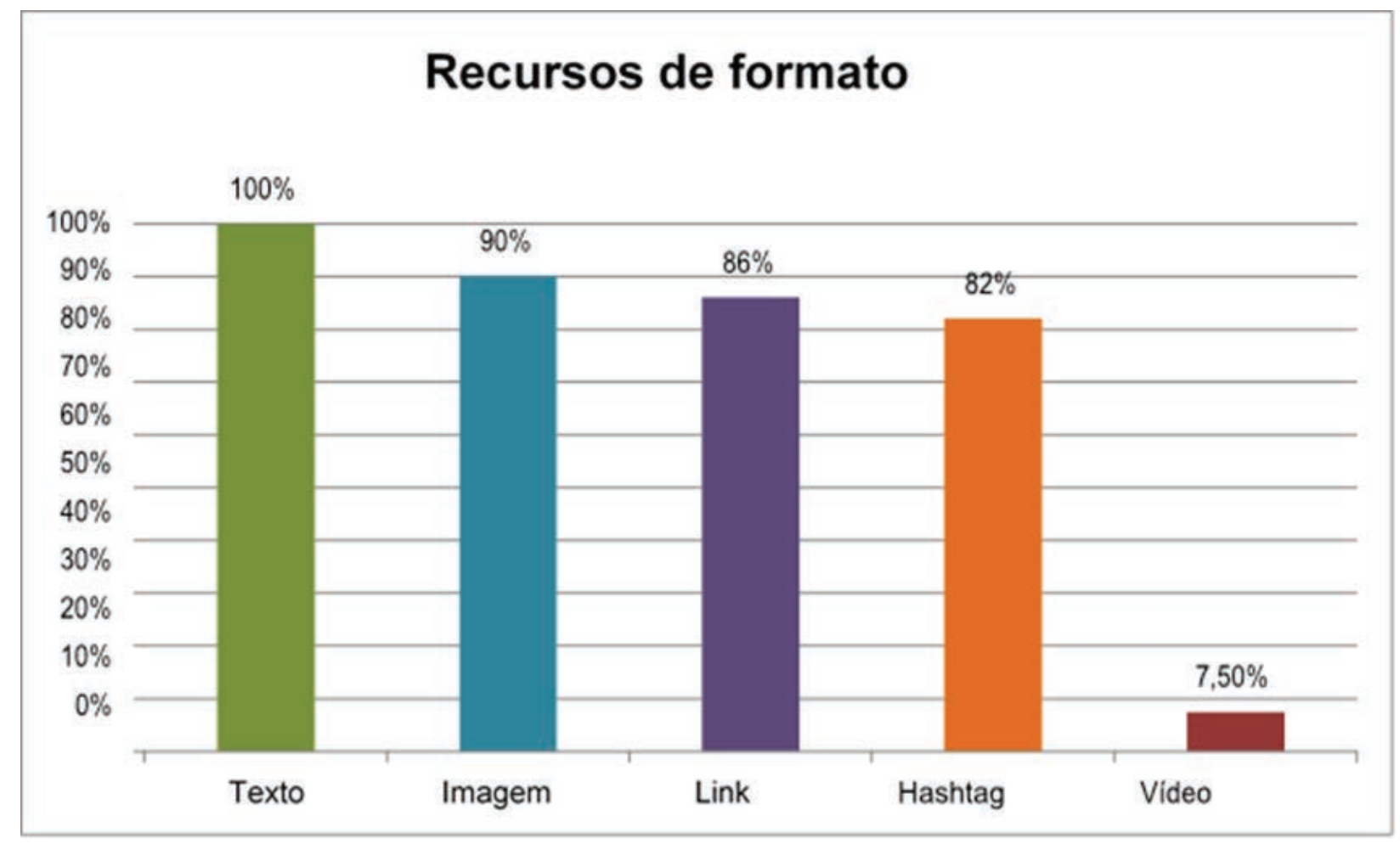

Gráfico 3 - Percentual de ocorrência dos recursos de formato nos posts* Fonte: Os autores (2017).

*Total de posts: 132.

É interessante observar paralelos entre esses resultados e os números encontrados em trabalhos semelhantes, como o de Rocha ${ }^{21}$, que estudou as páginas do Facebook do Jardim Botânico (JB), do Museu de Astronomia e Ciências Afins (Mast), do Museu Ciência e Vida (MCV) e do Planetário, todas instituições do Rio de Janeiro. Enquanto a presença de textos ocorre em 100\% das postagens da Fiocruz consideradas nesta pesquisa, os resultados obtidos por Rocha (2016) variam entre 92\% e 100\%. Quanto à utilização de imagens, 90\% dos posts da página da Fiocruz apresentam este recurso, enquanto este percentual varia entre $65 \%$ e $100 \%$ nas fanpages avaliadas por Rocha ${ }^{21}$. Já sobre o uso de links, o índice encontrado nesta pesquisa (86\%) supera consideravelmente o maior percentual registrado por Rocha, que foi de 33\%. O mesmo acontece com a ocorrência de hashtags, que no Facebook da Fiocruz aparece 
em $82 \%$ dos posts, enquanto nas páginas analisadas por Rocha ${ }^{21}$ o percentual varia entre $15 \%$ e 23\%. Já os vídeos são veiculados em $7,5 \%$ das postagens analisadas nesta pesquisa e apenas $2 \%$ na página com a maior ocorrência registrada por Rocha ${ }^{21}$.

\section{Engajamento}

O número de engajamento corresponde ao resultado da soma de 'curtidas', 'comentários' e 'compartilhamentos' e permite mensurar a participação do público nas postagens de uma fan page do Facebook. No período pesquisado, a média total de engajamento foi de 347 por postagem. Se considerarmos apenas as publicações sobre zika/microcefalia, este número sobe para 987, evidenciando um envolvimento significativamente maior do público com o tema. Foi observada, porém, grande variação no número de engajamento mesmo entre os posts sobre zika/microcefalia: dos 132 analisados, 110 tiveram engajamento menor que a média (987), enquanto a publicação com mais interações, publicada em dezembro/2015 e classificada na categoria 'Boatos/Esclarecimentos', chegou sozinha a mais de 33 mil de engajamento. Dezembro/2015 foi justamente o mês que atingiu a maior média de engajamento, 2315. O Gráfico 4 mostra a média de engajamento em cada mês das postagens sobre zika/microcefalia.

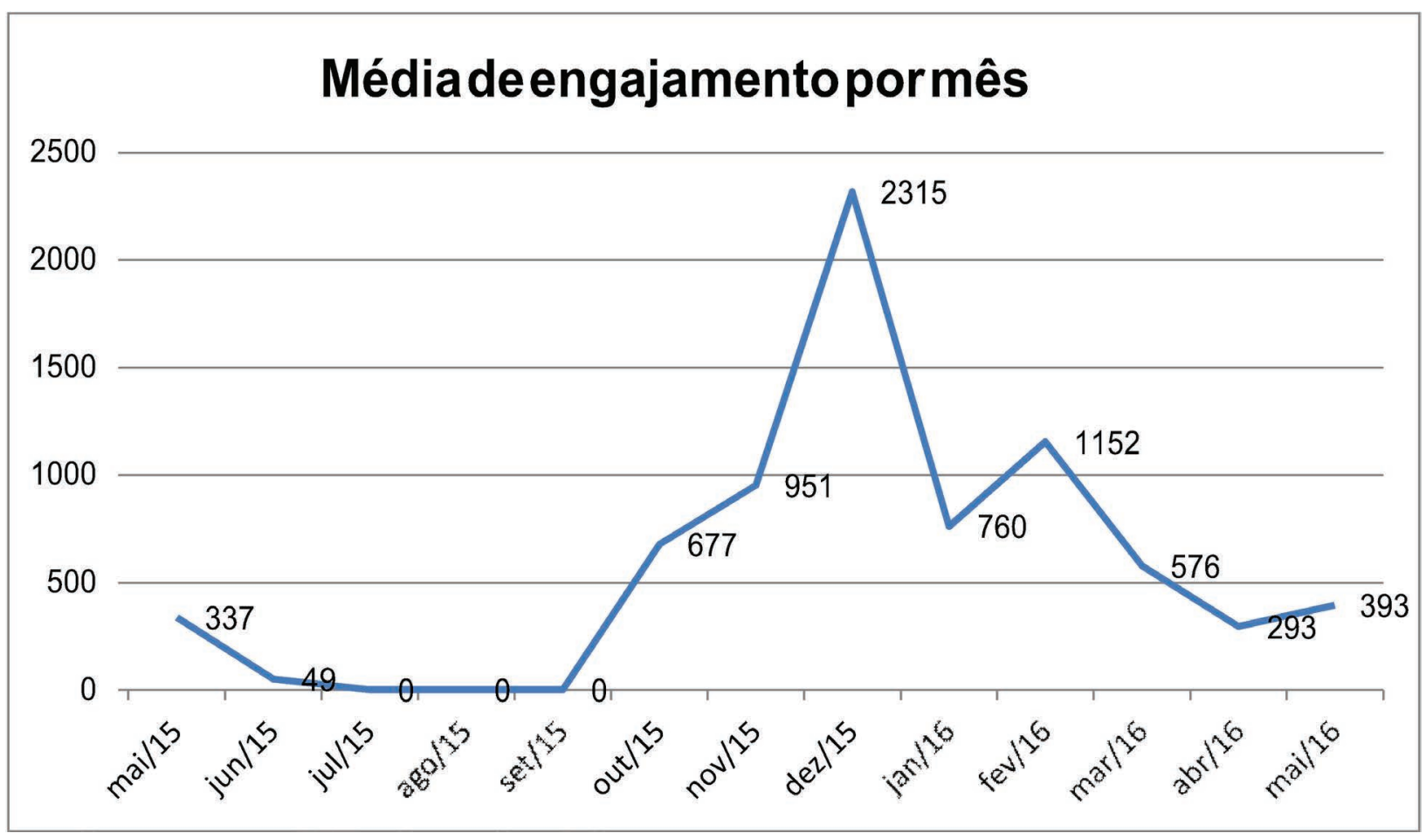

Gráfico 4 - Média de engajamento das postagens sobre zika/microcefalia por mês Fonte: Os autores (2017).

Numa análise por categoria, os posts classificados como 'Boatos/Esclarecimentos' foram os que registraram maior média de engajamento (4332). Nessa categoria, apenas 4 das 12 publicações tiveram desempenho de engajamento menor que a média dos posts sobre zika/microcefalia (987). Por outro lado, nas categorias 'Orientações/Dúvidas/Informações' e 'Novidades/Resultados/Descobertas', a maioria dos posts ficou abaixo da média ( 9 de 13 e 26 de 34, respectivamente). Isto significa que das três categorias com maior média de interações, apenas em 'Boatos' este número reflete uma tendência dos posts sempre gerarem grande engajamento. Nas outras duas, a média é alterada por uma minoria de posts que obtiveram melhor desempenho. O Gráfico 5 apresenta a média de engajamento de todas as categorias. 


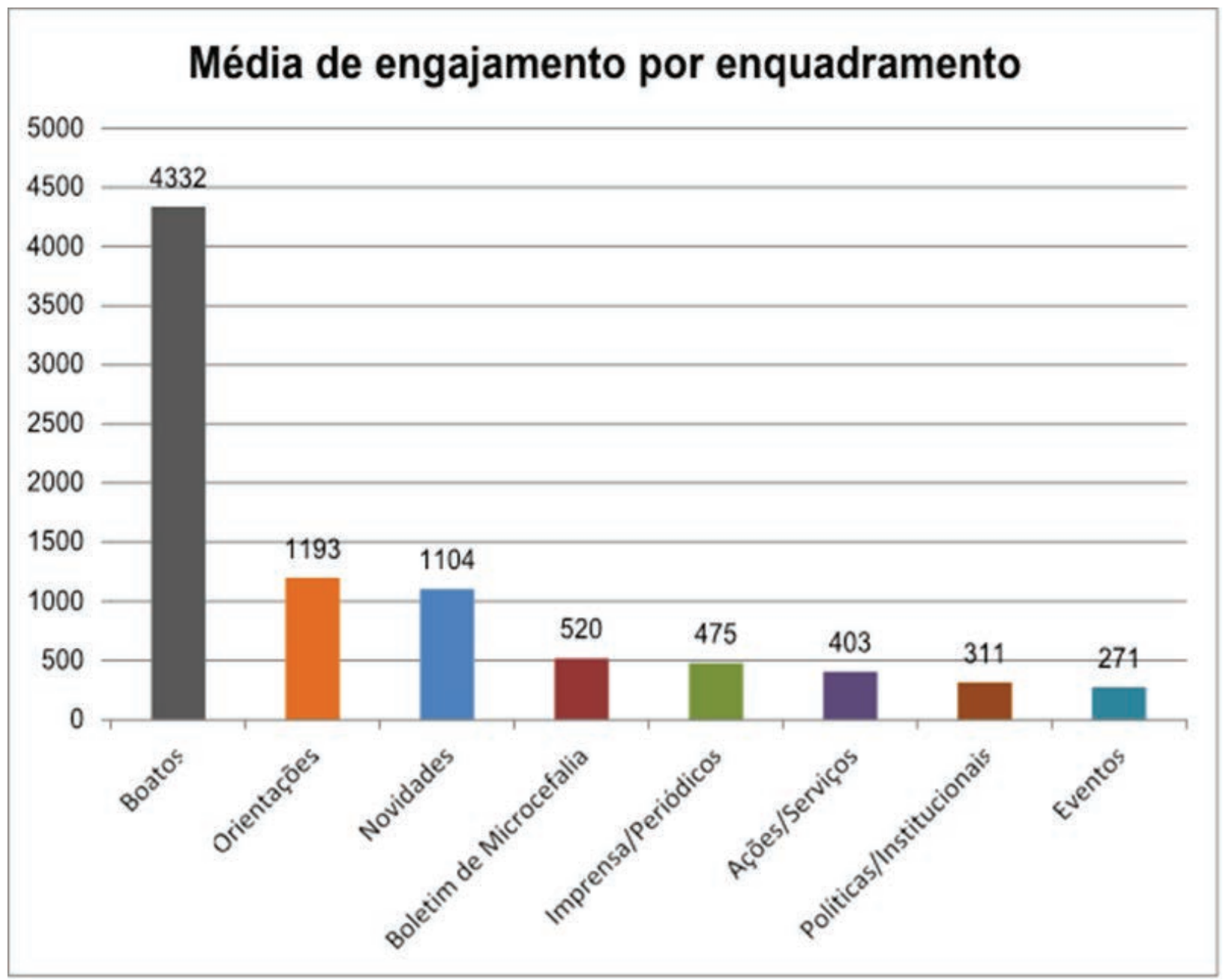

Gráfico 5 - Média de engajamento das postagens por enquadramento Fonte: Os autores (2017).

\section{Resultados da análise dos comentários}

Para a análise qualitativa, foram selecionados os cinco posts com o maior número de engajamento dos 132 estudados, listados no Quadro 1. Todos foram publicados no momento de maior média de engajamento de todo o período estudado, entre novembro/2015 e março/2016, e estão incluídos nas três categorias com maior média de engajamento. 
Quadro 1 - Os cinco posts com maior engajamento

\begin{tabular}{|c|c|c|c|c|}
\hline Post & Data & Descrição & Enquadramento & Engajamento \\
\hline 1 & 08/12/2015 & $\begin{array}{l}\text { Esclarecimento de boato de } \\
\text { WhatsApp sobre a relação entre } \\
\text { zika e problemas neurológicos em } \\
\text { crianças e idosos }\end{array}$ & $\begin{array}{l}\text { Boatos/ } \\
\text { Esclarecimentos }\end{array}$ & $\begin{array}{l}\text { Curtidas: } 11133 \\
\text { Comentários: } 2990 \\
\text { Compartilhamentos: } 19329 \\
\text { Engajamento: } 33452\end{array}$ \\
\hline 2 & $17 / 11 / 2015$ & $\begin{array}{l}\text { Informação sobre as diferenças } \\
\text { entre os sintomas da zika, dengue e } \\
\text { chikungunya }\end{array}$ & $\begin{array}{l}\text { Orientações/ Dúvidas/ } \\
\text { Informações }\end{array}$ & $\begin{array}{l}\text { Curtidas: } 914 \\
\text { Comentários: } 56 \\
\text { Compartilhamentos: } 6120 \\
\text { Engajamento: } 7090\end{array}$ \\
\hline 3 & $14 / 03 / 2016$ & $\begin{array}{l}\text { Divulgação de resultado de pesquisa } \\
\text { da Fiocruz sobre o vírus Zika atingir } \\
\text { a placenta em qualquer fase da } \\
\text { gestação }\end{array}$ & $\begin{array}{l}\text { Novidades/ } \\
\text { Resultados/ } \\
\text { Descobertas }\end{array}$ & $\begin{array}{l}\text { Curtidas: } 2075 \\
\text { Comentários: } 153 \\
\text { Compartilhamentos: } 4860 \\
\text { Engajamento: } 7088\end{array}$ \\
\hline 4 & $05 / 02 / 2016$ & $\begin{array}{l}\text { Divulgação de resultado de estudo } \\
\text { da Fiocruz que detectou o vírus Zika, } \\
\text { com potencial de infecção, na urina } \\
\text { e na saliva }\end{array}$ & $\begin{array}{l}\text { Novidades/ } \\
\text { Resultados/ } \\
\text { Descobertas }\end{array}$ & $\begin{array}{l}\text { Curtidas: } 2104 \\
\text { Comentários: } 211 \\
\text { Compartilhamentos: } 4514 \\
\text { Engajamento: } 6829\end{array}$ \\
\hline 5 & $16 / 01 / 2016$ & $\begin{array}{l}\text { Anúncio de kit produzido pela } \\
\text { Fiocruz para diagnóstico simultâneo } \\
\text { de zika, dengue e chikungunya }\end{array}$ & $\begin{array}{l}\text { Novidades/ } \\
\text { Resultados/ } \\
\text { Descobertas }\end{array}$ & $\begin{array}{l}\text { Curtidas: } 2035 \\
\text { Comentários: } 108 \\
\text { Compartilhamentos: } 2465 \\
\text { Engajamento: } 4608\end{array}$ \\
\hline
\end{tabular}

Fonte: Os autores (2017).

O primeiro post teve engajamento aproximadamente 5 vezes maior que o segundo colocado e 33 vezes maior que a média de engajamento das publicações sobre zika/microcefalia. Publicado em 8 de dezembro de 2015, ele apresenta mais de 20 linhas de texto em dois parágrafos, sem a divulgação de link, e acompanha uma foto do mosquito Aedes Aegypt. Em resumo, o corpo do texto desmente um boato propagado em grupos de WhatsApp, divulgando informações científicas oficiais, e incentiva os leitores a buscar fontes seguras de informação. O uso dos termos 'boato' e 'informações desencontradas' desqualificam o conteúdo da mensagem do WhatsApp, em contraposição às expressões 'seriedade', 'transparência', 'fundamentação científica' e 'fontes seguras e confiáveis', relacionadas à própria Fiocruz.

A participação do público na postagem, com mais de dois mil comentários, 10 mil curtidas e quase 20 mil compartilhamentos, foi intensa. Além de buscar interação com a página, os usuários também dialogaram entre si, respondendo e curtindo comentários de outras pessoas. Dos dez comentários de maior engajamento selecionados para análise qualitativa, todos foram postados por perfis femininos. Dentre os destaques, três deles apresentaram desconfiança em relação à Fiocruz e às informações publicadas, três destacaram a importância da prevenção individual pela eliminação dos focos do mosquito, dois trouxeram relatos pessoais sobre casos da doença na família e um atribui a culpa pela epidemia à facilidade na entrada de estrangeiros no Brasil (em referência à chegada do vírus no país). Como é possível perceber, nem sempre os comentários abordaram o conteúdo da postagem (o boato), mas utilizaram o espaço para levantar outras questões. Não há resposta da página da Fiocruz a qualquer comentário feito neste post.

A segunda publicação selecionada para a análise é uma postagem com apenas quatro linhas de texto, mas com bastante conteúdo textual na tabela informativa anexada como imagem. Esta publicação aborda, de forma didática, as diferenças entre os sintomas da zika, dengue e chikungunya. Vale destacar que o 
número de curtidas e comentários desta postagem é menor do que o das outras três postagens seguidas da tabela, porém, ela apresenta muito mais compartilhamentos (mais de seis mil). Isso mostra que a principal ação instigada no público pela postagem foi a de disseminar as informações contidas nela. Dos comentários analisados, cinco são de perfis femininos e cinco de perfis masculinos, e todos apresentam poucas curtidas e interações. Três deles observam a pouca diferença entre os sintomas, um parabeniza a instituição pelo post, e há outro relato pessoal de adoecimento. A manifestação de medo e/ou incerteza é observada duas vezes. Por fim, um comentário chama a atenção para a responsabilidade individual e governamental na prevenção. Nesta postagem, também, não há resposta da Fiocruz a qualquer comentário.

O terceiro post com mais engajamento divulgava o resultado de estudo da Fiocruz que concluiu que o vírus Zika atinge a placenta em qualquer fase da gestação. Ele apresenta cinco linhas de texto carregado no Facebook, associado a uma imagem de microscopia. A postagem cita vários termos do mesmo campo semântico (placenta, gestação, bebês, parto) e começa com uma afirmativa: 'Zika atinge placenta em qualquer fase da gestação' - que parece não querer deixar margem para contestação. Sobre os comentários analisados, nove foram de perfis femininos. O mais relevante comentário em termos de interação com outros usuários recebeu 62 curtidas e 5 respostas. Os outros não tiveram expressão neste quesito. Há dois relatos de casos pessoais da doença. Em um deles é clara a manifestação de medo, em outro de necessidade de precaução. Nesta postagem, destacam-se cinco comentários que trazem perguntas, embora mais uma vez não tenha havido qualquer resposta da página da Fiocruz.

A quarta postagem trazia o resultado de um estudo da Fiocruz que detectou o vírus Zika com potencial de infecção na urina e saliva. Mais uma vez foi utilizado link com imagem e texto carregados automaticamente. Neste caso, o enunciado no corpo do post era a fala de uma pesquisadora, enquanto o texto do link descrevia o resultado do estudo. A imagem veiculada pelo post era de uma cientista em laboratório. As expressões utilizadas remetem à inovação e descoberta ('primeira vez', 'novos paradigmas', 'responde uma pergunta', 'estudo pioneiro'), embora apareça a necessidade de mais estudos para o 'entendimento da relevância' da informação. Todos os comentários da análise são de perfis femininos. Destaca-se aqui um comentário com sete parágrafos e link com críticas direcionadas à Fiocruz e sua presidência, pela discordância em relação à divulgação do resultado do estudo sobre o vírus Zika na saliva e urina, caracterizado como 'irresponsável, inconsequente e precipitada'. Ele recebe 105 curtidas e 46 respostas, uma delas da própria página da Fiocruz defendendo o posicionamento da instituição utilizando o argumento da transparência. Esta é a única vez na análise que a página responde a um comentário. Em contraponto, há dois perfis que exaltam positivamente a Fiocruz, três comentários que apresentam perguntas (não respondidas), três relatos de adoecimentos e, em pelo menos quatro, manifestações de medo. Há, ainda, duas menções a boato que relaciona microcefalia e vacina contra a rubéola e uma a questionamentos quanto aos mosquitos transgênicos.

O quinto post com mais engajamento apresenta um enunciado de cinco linhas, com dois links para a Agência Fiocruz de Notícias e uma imagem anexada. A imagem veiculada é de pequenos tubos de ensaio e uma pipeta em laboratório. O enunciado exalta, pelo menos, três vantagens atribuídas ao produto desenvolvido pela Fiocruz e também divulga 'Especial sobre o vírus zika', com conteúdo jornalístico institucional. Dos dez comentários analisados desta postagem, sete são de perfis femininos, oito parabenizam a instituição pela inovação, todos são curtos e diretos. Há dois relatos de casos pessoais de suspeita de zika, dois com perguntas à instituição (sem resposta).

A análise qualitativa destes cinco posts permite desenvolver algumas reflexões mais gerais, ainda que seja necessário ponderar as limitações trazidas pelo número pequeno de unidades analisadas. Sobre o primeiro post, é preciso destacar o grande engajamento instigado por ele, assim como foi observado nas publicações classificadas no enquadramento 'Boatos/Esclarecimentos'. Este alto índice de participação demonstra o interesse do público em fontes de informação sobre a zika/microcefalia que abordem e dialoguem com os diversos rumores disseminados em diferentes redes sociais, como o WhatsApp. 
Da parte dos enunciados das postagens, é possível verificar que a ciência e os cientistas, assim como a Fiocruz, são retratados por um viés positivo. Já os comentários possibilitam compreender algumas das questões instigadas pelo tema, como a reiteração de emoções como medo, desconfiança e dúvida - embora também haja considerável número de manifestações de respeito e confiança em relação à Fundação.

Outro dado importante é a pouca frequência com a qual a instituição responde aos comentários da audiência - apenas em um dos 50 analisados a Fiocruz se manifesta, se defendendo de acusações e buscando preservar a sua imagem, em detrimento de esclarecer dúvidas apresentadas pelo público. Levando em consideração que os posts e os comentários analisados aqui foram os de maior engajamento, esta ausência se torna ainda mais significativa. Em que pese a dificuldade em lidar com um número enorme de interações, a falta de resposta ao público parece caracterizar uma comunicação unidirecional, na qual a instituição perde a oportunidade de um diálogo mais direto com o público. Estes dados, assim como os de Rocha ${ }^{21}$, indicam que a presença de uma instituição nas novas mídias não significa, necessariamente, a mudança de alguns paradigmas em termos de comunicação com o público.

\section{Considerações finais}

A partir da análise dos enquadramentos dos posts, foi possível conceber qual imagem de 'ciência' foi veiculada no contexto da zika/microcefalia pela Fiocruz no Facebook. O uso de signos da ciência foi utilizado para conferir credibilidade e validação sobre os conteúdos divulgados pela página, apresentando claramente um viés positivo e de valorização do trabalho científico e da própria instituição. Isso se deu em contraponto ao cenário marcado por sentimentos de incerteza, instabilidade e risco observado na epidemia por outros pesquisadore ${ }^{1,7,8,82}$. O mesmo cenário, aliás, também foi evidenciado pela análise dos comentários em nossa pesquisa, que mostrou a presença constante de manifestação de emoções de medo, desconfiança e dúvida - apesar de muitos registros, também, de respeito, confiança e apreço pela Fiocruz como instituição.

A pluralidade de enfoques dos posts também parece indicar que a Fiocruz buscou dialogar com um público mais amplo do que apenas os pesquisadores, estudantes e profissionais inseridos em sua rede de vínculos de atuação. Se analisadas as categorias de enquadramento em função do engajamento, 'Boatos/ Esclarecimentos', 'Orientações/Dúvidas/Informações' e 'Novidades/Resultados/Descobertas' receberam mais atenção do público. Neste caso, verifica-se o potencial do Facebook como uma ferramenta importante de divulgação científica, mais do que de comunicação entre pares.

As publicações abordando boatos merecem uma análise especial. Ao abordar e combater diretamente essas narrativas em sua página, a Fiocruz disputou a produção de sentidos sobre a epidemia com essas fontes, de credibilidade duvidosa, mas que ganharam visibilidade entre parte da população. Estas publicações foram as que obtiveram o maior número de engajamento, demonstrando o interesse do público por fontes de informação mais oficiais sobre as questões levantadas pelos boatos. Por outro lado, a baixa frequência com a qual a instituição respondeu aos comentários da audiência é outro ponto que merece destaque. Ainda que considerada a dificuldade em lidar com um número muito alto de comentários, a falta de interação caracteriza uma comunicação unidirecional e a perda de uma importante oportunidade de diálogo direto com um público que estava com medo e confuso.

Sobre o formato das postagens, os dados desta pesquisa indicam a opção pela utilização de recursos mais tradicionais. A página da Fiocruz variou e experimentou pouco em relação aos diversos formatos possibilitados pelo Facebook. Predominou o uso de imagens estáticas, textos e links em detrimento de vídeos (com poucas ocorrências) e gifs (com nenhuma ocorrência). Estes últimos são formatos que, segundo Rocha $^{21}$,geram maior tráfego e engajamento na rede. Tais dados podem demonstrar tanto um posicionamento institucional mais avesso à utilização desses recursos (no caso dos gifs e de outras possibilidades menos 
tradicionais de comunicação) e/ou, também, falta de fôlego para aproveitar o potencial das redes a partir, neste caso, da preparação de materiais específicos para o Facebook.

Tanto os dados sobre interação quanto sobre formato corroboram os resultados encontrados por Rocha' ${ }^{21}$, que indicam que a presença de uma instituição nas novas mídias não significa, necessariamente, a mudança de alguns paradigmas em termos de comunicação com o público. Assim como nesta análise, as páginas estudadas por Rocha ${ }^{21}$ não tinham como prática responder aos comentários do público nem estimular o diálogo, além de se utilizar de formatos com menor potencial de engajamento.

É preciso destacar ainda as limitações deste estudo. A metodologia escolhida permitiu conceber um panorama a partir unicamente da análise dos posts. Assim, ficou de fora desta pesquisa a compreensão sobre os objetivos determinados pela equipe administradora da página da Fiocruz, que poderiam dar mais esclarecimentos sobre a estratégia de gestão da rede social pela instituição. Além disso, o pequeno (embora significativo dentro do universo total, pelo seu grande engajamento) número de comentários estudados também se configura como uma limitação do estudo. Ainda assim julgamos que os resultados aqui apresentados, a partir da análise da principal rede social mundial e sobre a principal instituição de saúde pública brasileira, trazem importantes reflexões para as áreas de comunicação e saúde e divulgação da ciência. Reiteramos que, devido aos poucos estudos na área, o universo da realidade na ciência, saúde e redes sociais ainda é praticamente desconhecido no Brasil.

\section{Referências}

1. Aguiar R, Araújo IS. A mídia em meio às "emergências" do vírus Zika: questões para o campo da comunicação e saúde. Rev Eletron Comun Inf Inov Saude [Internet]. 2016 jan.-mar. [citado em 2018 jan. 23];10(1):1-15. Disponível em: https://www.reciis.icict.fiocruz.br/index.php/reciis/article/view/1088

2. Centro de Gestão e Estudos Estratégicos (BR). A ciência e a tecnologia no olhar dos brasileiros. Percepção pública da C\&T no Brasil: 2015 [Internet]. Brasília, DF: Centro de Gestão e Estudos Estratégicos; 2017 [acesso em 2018 fev. 12]. Disponível em: https://www.cgee.org.br/ documents/10182/734063/percepcao web.pdf

3. Cossetti MC. Facebook revela dados do Brasil na CPBR9 e WhatsApp 'vira ZapZap' [Internet]. O Globo (Grupo Globo). 2016 jan. 8 [citado em 2018 fev. 10]:TechTudo. Disponível em: https://www.techtudo. com.br/noticias/noticia/2016/01/facebook-revela-dados-do-brasil-na-cpbr9-e-whatsapp-vira-zapzap.html

4. World Health Organization. The history of zika virus [Internet]. Geneva: The Organization; [2017] [cited 2018 Jan 22]. Available from: http://www.who.int/emergencies/zika-virus/timeline/en/

5. Ministério da Saúde confirma relação entre vírus Zika e microcefalia. 2015 nov. 30 [citado em 2018 jan. 22]. In: Blog da Saúde [Internet]. Brasília: Ministério da Saúde; 2015. Disponível em: http://www.blog. saude.gov.br/index.php/combate-ao-aedes/50399-ministerio-da-saude-confirma-relacao-entre-virus-zikae-microcefalia

6. Wentzel M. Zika: OMS declara emergência internacional por microcefalia [Internet]. BBC News Brasil (BBC News). 2016 fev. 01 [acesso em 2018 jan. 23]. Disponível em: http://www.bbc.com/portuguese/ noticias/2016/02/160201 oms zika mw rb

7. Garcia MP. Disseram por aí: deu zika na rede! Boatos e produção de sentidos sobre a epidemia de zika e microcefalia nas redes sociais [dissertação]. Rio de Janeiro: Fundação Oswaldo Cruz; 2017.

8. Antunes MN, Alves W, Gouveia FG, Oliveira AE, Cardoso, JM. Arquivos visuais relacionados ao vírus Zika: imagens no Instagram como parte da constituição de uma memória da epidemia. Rev Eletron Comun Inf Inov Saude [Internet]. 2016 jul.-set. [acesso em 2018 jan. 30];10(3):1-13. Disponível em: https://www. reciis.icict.fiocruz.br/index.php/reciis/article/view/1175

9. Centro Regional de Estudos para o Desenvolvimento da Sociedade da Informação (Cetic.br). TIC Domicílios 2015: apresentação sobre os principais resultados [Internet]. São Paulo: O Centro; 2016 set. 13 [acesso em 2018 fev. 11]. Disponível em: https://cetic.br/media/analises/tic domicilios 2015 coletiva de imprensa2015

10. Nisbet MC, Scheufele DA. What's next for science communication? Promising directions and lingering distractions. Am J Bot. 2009 Oct;96(10):1767-78. doi: http://dx.doi.org/10.3732/ajb.0900041 
11. Garbin $\mathrm{H}$, Guilam $\mathrm{M}$, Neto $\mathrm{A}$. Internet na promoção da saúde: um instrumento para o desenvolvimento de habilidades pessoais e sociais. Physis [Internet]. 2012 [acesso em 2018 fev. 11];22(1):347-63. Disponível em: http://www.scielo.br/scielo.php?script=sci arttext\&pid=S0103-73312012000100019

12. Wilcox C. Guest Editorial. It's time to e-volve: taking responsibility for science

13. communication in a digital. Biol Bull [Internet]. 2012 Apr [cited 2018 Nov. 02];222:85-7. Available from: http://www.biolbull.org/content/222/2/85.long

14. Antunes MN, Silva CH, Guimarães MCS, Rabaço MHL. Monitoramento de informação em mídias sociais: o e-Monitor Dengue. Transinformação [Internet]. 2014 jan.-abr. [citado em 20018 fev. 11];26(1):9-18. Disponível em: http://www.scielo.br/scielo.php?script=sci arttext\&pid=S0103-37862014000100002

15. Facebook atinge marca de 1 bilhão de usuários todos os dias [Internet]. São Paulo: G1, Tecnologias e Games; 2016 abr. 28 [acesso em 2018 fev. 13]. Disponível em: http://g1.globo.com/tecnologia/ noticia/2016/04/facebook-atinge-marca-de1-bilhao-de-usuarios-todos-os-dias.html

16. Recuero R. A rede é a mensagem: efeitos da difusão de informações nos sites de rede social [Internet]. In: Vizer E., organizador. Lo que mcluhan no previó. Buenos Aires: La Crujía; 2012 [acesso em 2018 fev. 15]. p. 205-223; [versão rascunho/draft]. Disponível em: http://www.raquelrecuero.com/arquivos/ redemensagem.pdf.

17. Portugal J. Fiocruz eleita a melhor instituição de saúde pública do mundo [Internet]. Rio de Janeiro: Abrasco. 2006 ago. 22 [citado em 2018 fev. 11]. Disponível em: https://www.abrasco.org.br/site/ eventos/congresso-brasileiro-de-saude-coletiva/fundacao-oswaldo-cruz-e-a-melhor-do-mundo-na-areade-saude-publica/122/

18. Righetti S, Moraes FT. Fiocruz é a melhor instituição de pesquisa do Brasil em ranking da Universidade de Leiden [Internet]. Folha de S. Paulo (Grupo Folha). 2014 jun. 2:Ciência. Disponível em: https:// www1.folha.uol.com.br/ciencia/2014/06/1463518-fiocruz-embrapa-e-inpe-lideram-pesquisa-no-pais-diznovo-ranking.shtml

19. Fiocruz conquista Prêmio José Reis de Divulgação Científica 2015 [Internet]. Rio de Janeiro: Portal Fiocruz, Informação e Comunicação, Notícias; 2015 jun. 18 [acesso em 2018 fev. 09]. Disponível em: https://portal.fiocruz.br/noticia/fiocruz-conquista-premio-jose-reis-de-divulgacao-cientifica-2015

20. Bardin L. Análise de conteúdo. Lisboa: Edições 70; 1977.

21. Ramalho M, Massarani L, Castrillón TA, Polino C, Vara AM, Crúz-Mena J et al. Ciência em telejornais: uma proposta de ferramenta para análise de conteúdo de notícias científicas. In: Massarani $L$, Ramalho M., organizadoras. Monitoramento e capacitação em jornalismo científico: a experiência de uma rede ibero-americana. Rio de Janeiro: Museu da Vida, Casa de Oswaldo Cruz, Fiocruz; Quito: Ciespal; 2012. p.11-24.

22. Rocha LMP. Instituições de divulgação científica no Facebook: como Jardim Botânico, MAST, MCV e Planetário dialogam com o público por esta rede social [Monografia]. Rio de Janeiro: Fundação Oswaldo Cruz; 2016.

23. Nunes J, Pimenta DN. A epidemia de Zika e os limites da saúde global. Lua Nova [Internet]. 2016 [acesso em 2018 fev. 16];98:21-46. Disponível em: http://www.scielo.br/scielo.php?pid=S0102-

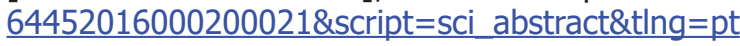

